\title{
Farmlet testing of the DairyNZ Conservation Demo
}

\author{
C.G. ROACH, P.C. BEUKES and A.J. ROMERA \\ DairyNZ, Private Bag 3221, Hamilton \\ Chris.Roach@dairynz.co.nz
}

\begin{abstract}
The DairyNZ Modelling Group has developed a model called the Conservation Demo to assist in identifying and conserving surplus pasture on dairy farms. The hypothesis was that a computer algorithm would be able to make decisions concerning timing and amount of conservation similar to an experienced pasture manager. Weekly grazing decisions on DairyNZ farmlets, with stocking rates of 2.6 to 3.5 cows/ ha, were made by a team of research staff over three years. The model was run for each farmlet to compare its recommendations with the conservation decisions made by the research team. In spring on all farmlets and in summer on the higher stocked farmlets, the model was more conservative than the team in recommending paddocks to be closed in all seasons. In summer 2011/12 the recommendations from the model were more variable week-to-week (paddocks being closed one week and not the next), and on the lower stocked farmlet the model was more aggressive than the team. The Conservation Demo is a useful tool for identifying surplus pasture if the output is moderated by the farm manager, and the use of a feed wedge in conjunction with the model would improve the decisions. However the model requires pasture covers for each paddock, ideally at least weekly, and currently $<20 \%$ of dairy farmers collect these data on a regular basis.
\end{abstract}

\section{Introduction}

Accurate and timely identification of surplus pasture is important on dairy farms for conservation of feed for periods of deficit, and for maintaining the quality of pastures grazed by the milking herd. Being aggressive and closing too much of the farm area for conservation results in underfeeding of the cows or supplements having to be fed. Being conservative and closing too little of the farm area results in higher post-grazing residuals that lead to decreased pasture quality at subsequent grazings (Lee et al. 2008) and this can reduce milksolids production (Hoogendoorn et al. 1988). The DairyNZ Modelling Group has developed a model called the Conservation Demo to assist in identifying surplus pasture. The model determines if a surplus exists, and whether it is a true surplus, and recommends which paddocks to close for conservation. This study set out to test the hypothesis that the
Conservation Demo would be able to make decisions concerning timing and amount of conservations equally as well as an experienced pasture manager.

\section{Methods}

\section{The Conservation Demo}

The Conservation Demo follows the pasture conservation rules developed by Macdonald (1997). These rules involve testing three conditions to identify if there is a pasture surplus and if the surplus can be harvested.

Condition 1: Is the average pasture cover (APC) on the grazing area greater than the required cover? The required cover is the mid-point between the target grazing residual and the target pre-grazing cover. This condition determines if a surplus exists.

Condition 2: Given the rotation length, will there be enough days for a break to grow back to the target pregrazing cover for the following rotation? This condition determines if there is a true surplus, i.e., if there will still be a surplus in the near future.

Condition 3: Is the cover of the highest yielding paddock (excluding paddocks already closed) greater than the target pre-grazing cover? This condition determines if the surplus can be harvested without compromising animal intakes.

If all three conditions are met, the Demo rechecks if the conditions are still met with the highest yielding paddock closed. If so, the Demo closes the paddock, and then rechecks the conditions for the next highest yielding paddock, and so on, until one of the conditions is not met.

\section{Model inputs}

The Conservation Demo requires the following data:

Paddock information: Paddock name/number, area and current pasture cover ( $\mathrm{kg} \mathrm{DM} / \mathrm{ha}$ ) of all paddocks.

Animal information: Herd size and feed required $(\mathrm{kg}$ DM/cow/day).

Pasture information: Target post-grazing residual, rotation length, and expected pasture growth during the next rotation ( $\mathrm{kg} \mathrm{DM} /$ ha/day).

In addition, a policy option for managing break size and rotation length when paddocks are closed for conservation needs to be selected:

Policy option 1: Light cut - fixed break size. After 
closing, a paddock is immediately cut and returned to the rotation. Therefore, the rotation length and break size do not change.

Policy option 2: Bulk cut - fixed break size. A closed paddock is left to accumulate growth. With this option, break size is maintained on the remaining grazing area. This means that rotation length has to be shortened because part of the grazing area is closed for a period of time.

Policy option 3: Bulk cut - variable break size. A closed paddock is left to accumulate growth. With this option, planned rotation length is maintained on the remaining grazing area. Therefore, break size has to be reduced because the grazing area is now smaller (excludes the closed paddock).

The model can be run using each of the policies in turn to compare the outcomes quickly.

\section{Model output}

The model runs the calculations for the three conditions, and lists which paddocks can be closed for conservation. A "step-by-step" button can be selected so that the user can see the calculations and outcomes for each condition, or if the "fast forward" button is selected, the model scrolls straight to the recommended list of paddocks to be closed. The user can change an input variable (e.g. policy option or expected pasture growth) and "fast forward" to see the impact on the number of paddocks recommended to be closed.

\section{Model assessment}

Each Tuesday, a team of five experienced pasture managers conducted a farm walk on the trial farmlets at DairyNZ Scott Farm. Members of the team used visual assessment, calibrated against quadrat cuts, of pasture cover in each paddock. After each farm walk the paddock covers were entered into a spreadsheet and a feed wedge (DairyNZ 2010) generated for each farmlet. The team then made the grazing decisions for the next week for each farmlet, including deciding which paddocks, if any, were to be closed for conservation. During the 2009/10 season there were eight farmlets on Scott Farm (Table 1). The model was run for each farmlet immediately following the weekly walk, prior to the team making the grazing decisions. The recommendations were compared with the team's decisions, and as a result of this, it was suggested that the farmlets could be used to test the model. In subsequent seasons, the model was run for each farmlet after the team had made the weekly grazing decisions so that the team's decisions were not influenced by the model's recommendations. The results presented in this paper are from the subsequent seasons (2010/11 and 2011/12).

The eight farmlets from the 2009/10 season (Table 1, Farmlets A, C, G to L) continued in the 2010/11 season, and an additional farmlet (E) with some cropping was also included. Data collection from all the farmlets finished at the end of May 2011.

In the 2011/12 season, two new larger farmlets were established: Farmlet $\mathrm{X}$ in pasture and similar to the previous Farmlet A, and Farmlet Y, also in pasture, but with a lower stocking rate and using less nitrogen fertiliser (Table 1).

From early September until early April each year, after the weekly grazing decisions had been made, the model was run for each farmlet. Actual values were used for the herd size, feed required, target post-grazing residual and rotation length inputs. Policy option 2 was used (bulk cut - fixed break size). For farmlets where crops were being grazed, or were about to be grazed, the feed required input was entered as the amount of pasture required. The expected pasture growth value was generated from a pasture growth model for each farmlet. The paddocks closed by the model were recorded. If the model closed no paddocks, or fewer paddocks than the team, the conditions not met were recorded.

The hypothesis was that the model would be able to make decisions concerning timing and amount of conservation similar to those of the team. Where the recommendations of the team and model differed, it needed to be determined whether the team or the

Table 1. Description of farmlets on DairyNZ Scott Farm in 2011 and 2012 seasons. Farmlets $\mathrm{G}$ to $\mathrm{L}$ are described by Clark et al. (2010)

\begin{tabular}{|c|c|c|c|c|c|c|}
\hline Farmlet & A & $\mathrm{C}$ & $\mathrm{E}$ & $\mathrm{G}, \mathrm{H}, \mathrm{I}, \mathrm{J}, \mathrm{K}, \mathrm{L}$ & $x$ & $\mathrm{Y}$ \\
\hline Size (ha) & 7 & 9 & 8 & 4 & 13 & 13 \\
\hline No. of paddocks & 14 & 18 & 16 & 8 & 26 & 26 \\
\hline Cows/ha & 3.3 & 2.6 & 3.5 & 3.5 & 3.2 & 2.6 \\
\hline $\mathrm{N}$ use $(\mathrm{kg} / \mathrm{ha} / \mathrm{yr})$ & 170 & 0 & 200 & ca. 400 & 150 & 50 \\
\hline Other details & & $11 \%$ crops & $\begin{array}{l}31 \% \\
\text { crops }\end{array}$ & $50 \%$ irrigated, I-L $25 \%$ crops & & \\
\hline Silage paddocks cut $2009-10$ & 13 & 16 & - & $1-7$ & - & - \\
\hline Silage paddocks cut $2010-11$ & 12 & 9 & 1 & $0-3.5$ & - & - \\
\hline Silage paddocks cut $2011-12$ & - & - & - & - & 18 & 18 \\
\hline
\end{tabular}



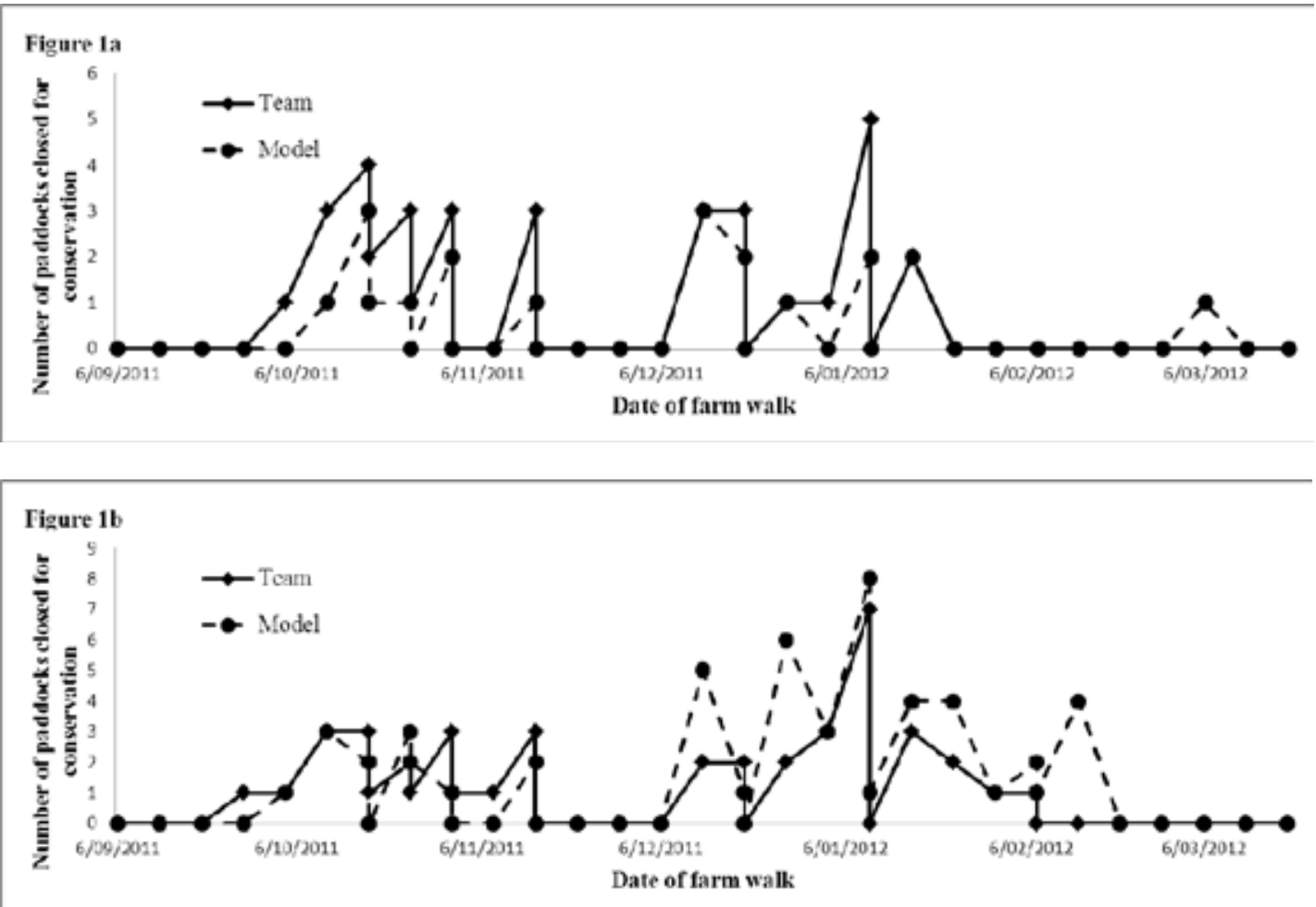

Fig. 1a \& 1b. Number of paddocks closed (team) or recommended to be closed (model) for farmlets $X$ (Figure 1a) and $Y$ (Figure 1b). Vertical lines denote paddocks harvested for silage, lines with negative slope denote grazing of previously closed paddocks.

model was correct. Only the team's decisions were implemented on the farmlets, so indicators were used to allow objective assessment of which method made the most correct decision, e.g., where more paddocks were closed than the model recommended, had the team closed too many paddocks or the model closed too few paddocks? The following indicators were used: whether APC on the grazed area the following week was above or below the required cover; whether grazing residuals in the following week were above or below target; whether supplements were fed; and whether pasture growth was above or below demand; in addition, for the team decisions if paddocks remained closed and were harvested for silage, and for the model if the number of paddocks recommended to be closed changed in the subsequent week. In each week that the team's and model's decisions differed, the method that had the most correct decision for each indicator scored 1 point, and the method with the highest points was judged to be correct for that week. For example, if the model closed fewer paddocks than the team, and grazing residuals during the following week were below the target 7-8 clicks on the rising plate meter, this suggests the team had closed too many paddocks, therefore the model scored a point on this indicator.

\section{Results and Discussion}

In the 2010/11 season, less silage was made than in a normal season. On the six smaller farmlets $(\mathrm{G}-\mathrm{L}), 0$ to 3.5 paddocks per farmlet were harvested for silage, and Farmlet $\mathrm{E}$ had one paddock harvested. On these farmlets the model did not recommend closing any paddocks in any weeks. In most weeks (69\%) this was due to Condition 1 not being met, with APC being less than the required cover. Due to the small number of paddocks harvested, and part-paddocks being harvested, no further comparison was undertaken.

Farmlet A had 12 paddocks harvested, and Farmlet $\mathrm{C}$ had 9 paddocks harvested. In some weeks the model and team agreed (35\% and $79 \%$ of weeks for farmlets A and $\mathrm{C}$ respectively), but in most weeks (59\%) the model recommended closing fewer paddocks on Farmlet A than the team. In each of the 16 weeks where the team closed more paddocks on a farmlet than the model, the team scored higher than the model using the indicators, scoring 4 or more points out of a possible 6 points. In the single week where the model closed more paddocks than the team (Farmlet A in early October), the model scored 5 points. Correlation coefficients between the number of paddocks closed each week by the team and by the model were 0.74 and 0.81 for Farmlets A and C respectively. 


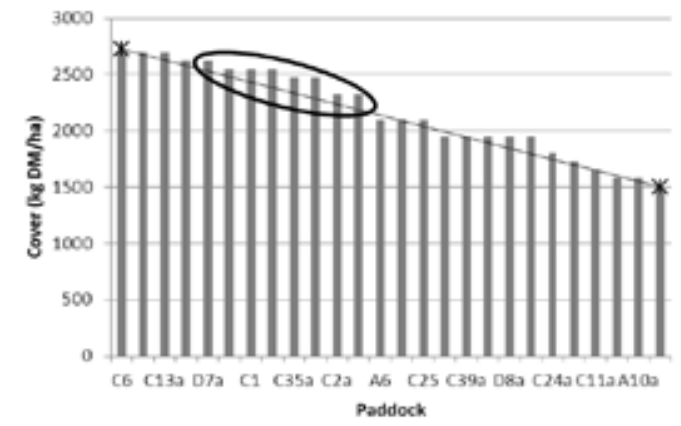

Figure 2. Example feed wedge showing a developing surplus (circled)

In the 2011/12 season, with the larger farmlets (X and $\mathrm{Y}$ ), more data was generated, with 18 paddocks harvested for silage on both farmlets. The conservation decisions by the model and the team agreed on Farmlets $\mathrm{X}$ and $\mathrm{Y}$ in $69 \%$ and $56 \%$ of weeks respectively. However, in spring the model tended to be more conservative than the management team, closing fewer paddocks on both farmlets (Figures 1a and 1b). In spring, in every instance where the model closed fewer paddocks, the reason was that Condition 1 was not met. During periods of high pasture growth, the outcome of Condition 1 was dependent on the date that the model was run. For example, on the 1 November 2011 the team closed three paddocks while the model recommended only one paddock be closed. Running the model four days later (after adjusting paddock covers for growth and grazings) resulted in an additional three paddocks being recommended for closing. When growth exceeds demand, APC is increasing, e.g., if growth is $70 \mathrm{~kg} \mathrm{DM} /$ ha/day and demand is $50 \mathrm{~kg} \mathrm{DM} / \mathrm{ha} /$ day, APC increases by $20 \mathrm{~kg} \mathrm{DM} / \mathrm{ha}$ each day. This can result in Condition 1 being met within a few days of it not being met.

In summer on the lower stocked farmlet $(\mathrm{Y})$, the model was more aggressive than the team, often closing more paddocks (Figure 1b). The results were also more variable, with paddocks closed one week not recommended to be closed the following week e.g., on the 14 February 2012 the model recommended closing four paddocks, but when run a week later recommended no paddocks be closed.

For both farmlets, where the team closed more paddocks than the model, the team scored higher than the model using the indicators, averaging 5.1 out of a possible 6 points. Eleven of these fifteen weeks were in spring, and the team was confident of continuing increases in pasture growth and APC, and, therefore, prepared to take some risks. Also, using a feed wedge, the team could identify a developing surplus (Figure 2 ) and could be proactive and close paddocks further down the rankings, while this is a capability the model does not have.
For Farmlet X, the one week (6 March) where the model closed more paddocks than the team, the team scored five out of six on the indicators. For Farmlet Y, in the 8 weeks where the model closed more paddocks than the team, the indicators were equal, with both the model and team scoring higher in 3 weeks each, and the outcome being drawn in the other 2 weeks. Seven of the eight weeks where the model closed more paddocks than the team were in summer, and the team was probably being more conservative in their decisions, as summer 2011/12 was characterised by a pattern of high rainfall events followed by extended dry periods. Correlation coefficients between the number of paddocks closed each week by the team and by the model were 0.86 and 0.76 for farmlets $\mathrm{X}$ and $\mathrm{Y}$ respectively.

\section{Conclusions}

Overall, the Conservation Demo is a useful tool to assist in identifying surplus pasture, and performed well when compared to a team of experienced pasture managers, making equal or better conservation decisions in $59 \%$ of the events tested, and similar decisions (one paddock different) in a further $20 \%$. In periods of rapidly improving pasture supply the decision rules implemented in the model do tend to be too conservative. During these periods the user should note the margin by which the conditions are met or not met, and moderate the model's output by closing more paddocks than recommended. Use of a feed wedge in conjunction with the model would further improve the decisions.

There are two main benefits in using the model to assist identifying surplus pasture: a) it uses simple logical calculations that have been proven (Macdonald 1997), without the need to manually calculate and recalculate the results as paddocks are closed for conservation; b) the model is quick to run, with the ability to test different scenarios.

As with any model, the data input affects the output. For this model most inputs are simple, measured data, and the most subjective input is the expected pasture growth rate. The user is able to "fast forward" the model using a range of pasture growth rates and see the impact this has on the number of paddocks recommended to be closed.

An obstacle for use of the model by dairy farmers is that it requires pasture covers for all paddocks in the grazing area, and many farmers do not regularly collect this information. It is estimated that $20 \%$ of dairy farmers do regular feed budgeting (Clark et al. 2006), and the number with regular and frequent assessment of pasture covers is likely lower, despite most other methods of identifying surplus pasture also requiring this information, including the one used by the team in this study. 


\section{ACKNOWLEDGEMENTS}

The authors wish to acknowledge Hemda Levy for her significant contribution to the development of the model, and assistance and training during the project. We also thank the DairyNZ Scott farmwalk team for allowing their conservation decisions to be used.

\section{REFERENCES}

Clark, C.E.F.; Clark, D.A.; Waugh, C.D.; Roach, C.G.; Glassey, C.B.; Woodward, S.L.; Minneé, E.M.K.; Woodfield, D.R. 2010. Systems to increase grazeable forage production in the Waikato: A progress report on the tall fescue and perennial ryegrass component of these systems. Proceedings of the New Zealand Grassland Association Volume: 72: 49-54

Clark, D.; Litherland, A.; Mata, G.; Burling-Claridge, R. 2006. Pasture Monitoring from Space, Proceedings of SIDE Conference, 26-28 June 2006, Invercargill. pp 108-123.
DairyNZ 2010. Farmfact 1-14. Feed wedges. Accessed 06/06/2012. http://www.dairynz.co.nz/file/ fileid/36306

Hoogendoorn C.J.; Holmes C.W.; Chu A.C.P. 1988. Grazing management in spring and subsequent dairy cow performance. Proceedings of the New Zealand Grassland Association 49: 7-10

Lee J.M.; Donaghy D.J.; Roche J.R. 2008. Effect of defoliation severity on regrowth and nutritive value of perennial ryegrass (Lolium perenne L.) dominant swards. Agronomy Journal 100: 308-314

MacDonald, K. 1997. Profitable Dairying. Occasional publication. NZ Rural Press. September 1997 
